\title{
SKILL ACQUISITION AND PERFORMANCE OF THE DYEING INDUSTRY IN ABEOKUTA, OGUN STATE
}

DOI: 10.36108/ljerhrm/2202.03.0131

OGUNJIMI, Fatai, Ayesebotan

Postgraduate Student, Kwara State University, Malete ogunjimifatai@gmail.com

MUSTAPHA, Rahman, Oladimeji

Senior Lecturer, Kwara State University, Malete rahmanmustpha717@gmail.com

and

\author{
ABDULRAHEEM, Issa \\ Senior Lecturer, Kwara State University, Malete \\ abdulraheemissa@gmail.com
}

\begin{abstract}
The current patronages in the dyeing industry recent are going down and discouraging due to the black box effect of the dyes' fastness and their reactive quality. This was not on unconnected with the exits of the older generations who are better adjudged experienced and well knowledgeable in the ionic and covalent bond structures of the existing ranges of fabrics in the market. This is done by making the right choice of the reactive dyes combinations or their preparations and applying the appropriate processing technologies implying skill issues.The broad objective of this study was to examine the effect of skill acquisition on the dyeing industry while the specific objective includes first investigating the effect of high education on the marginal returns in the dyeing industry. The second specific objective was to examine the effect of practice on the marginal returns in the industry. These two variables are considered crucial to organizational effective performance, particularly, in the dyeing industry. This survey was based on the population of 146 respondents drawn from the five zones (A to E, Abeokuta South Local Government) in the industry. The research method was quantitative. The research design was a cross-sectional one. The analysis technique used for the study was the multiple regression analysis. Stratified sampling techniques were adopted to carry out the research survey. The study revealed that practice as a variable had a very strong effect (found to be 0.2) on the marginal returns in the dyeing industry. High education also had a significant effect (abstracted to be 0.05) on the marginal returns in the dyeing industry. The study concluded that skill acquisition had a significant effect on the performance of the dyeing industry in terms of the marginal returns in the industry and therefore recommended that technical education should be subsidized or be free. Government should also encourage secondary and tertiary levels of education by an increase in the budget share of high vocational education. Measures for individuals, corporate organizations, and government revitalizing and preferring technical, and vocational training (TVET) to complement the conventional education type should be instituted by the policymakers, and the decision drivers, which will go a long way to aid the unemployed especially the university graduates as well as the other army of the jobless people.
\end{abstract}

Keywords: Abeokuta, Dyeing, industry performance, skill acquisition, 


\section{Introduction}

Dye skills depict the art of painting or adding to materials dyes making it look colorful and attractive. Skill acquisition is the ability to do something partly and well too according to Advance English Learner Dictionary. Doing something indicates a purposeful effort for achieving objectives and according to Irikefe (2017), this is the capacity and ability acquired through purposeful, systemic, and sustained effort to adaptively and smoothly carry out complex activities or job functions involving ideas (cognitive skills), things (technical skill) and or people (interpersonal skills). The skill enables the capacity of a person to observe and understand a situation and to act reasonably. It is the ability to use one's knowledge effectively in executing or performing a particular activity. It should be clear that skill is meaningless without the anticipated rewards

Adire is a compound word meaning Adi(Yoruba - tie) and re (Yoruba - dye), tie-dye. Adirewhich modification includes Kampalaand started as the business of adding traditional blue dye (indigo) extracted from Elu (Yoruba) leave on the tick white cloth (teru - Yoruba) to prolong the use before washings. The art of tie later cropped up for designing and modifying the plane whites tending practitioners to innovations and enterprise. MiniyaJojololaSoetan family first produced Adire cloth usingLonchocarpusCyanescens, known as "Elu-Aja" (Elu Leaf) which is the plant from which the traditional indigo blue dye is always produced and it was commonly found in Shaki and Iseyin of Oyo North in Nigeria, both towns close to Abeokuta. Adire was first produced inNapoleon (2020) said if you cannot do great things, do small things in a great way!

\section{Statement of Problem}

There was a drop in the business prospects due to the lack of analytical capability of the dyes preparationand skills applications and gross inadequacy of the knowledge of results from the perspectives of entrepreneurship due to the low levels of educational training. Dyes were easily washed off the fabrics. People had fear to have outings with traditional wears like Adire, Kampala, andBatikas well as Aso-okewhen raining. Excessive sweating caused multiple stains not only on underwear and the body but also associated skin problems as a result of inadequate hands-on specific practice in the tie-dye trainings as well as soft skills practical interventional measures.

\section{Research questions}

(i) To what extent does high education affect marginal returns in the dyeing industry?

(ii) To what extent does practice affect marginal returns in the dyeing industry?

\section{Research Objectives}

While the main aim of this study is to establish the effect of skill acquisition in the dyeing industry in Abeokuta, Ogun State the specific objectives were:

I. Examine the effect of high education on marginal returns in the dyeing industry

II. Examine the effect of practice on marginal returns in the dyeing industry

\section{Research Hypotheses}

(i) $\mathrm{H}_{01}$ : - High education does not have a significant effect on marginal returns in the dyeing industry

(ii) $\mathrm{H}_{02}$ : -Practice does not have a significant effect on marginal returns in the dyeing industry 


\section{Scope of the Study}

The research covered the small-scale, entrepreneurial business, as a case study of small firm dyeing industry, Abeokuta South Local Government Area of Ogun State, South-West Nigeria of which total population was 146 including the trainees, trainer, and clients/retailers. The survey was carried out between the first and second quarters the month of July and August) of the year 2021.

\section{Literature Review}

\section{Conceptual Review \\ Dyeing Business Evolution.}

The business evolution revered the $18^{\text {th }}$ century William Perkin who extracted mauve, silk dye yielding dye shades, fast to light. This was the beginning of the business to a chemist entrepreneur who opened his shop especially covering the reactive chemical dyes. In 1856, William Perkins' daring attempt to produce quinine for the treatment of malaria by oxidation of aromatic amines went completely wrong. Although he did not obtain quinine, he did obtain the first synthetic textile dye, violet mauvein (Perkin violet, aniline purple). This marked the beginning of the tar dye industry and the chemical-pharmaceutical industry that developed from it (Vera 2021). The intention was solving an endemic health problem but eventually the result ended up in a Chemist producing a dye mauvre, opening up a shop for business in dyeing products which was forever historic.Other chemists followed suit to discover various other dyes from coal tar. Yusuf, Mohd, Mohd, and Faqeer (2017) stated the most famous and highly prized color through the ages was Tyrian purple, noted in the Bible, a dye obtained from the hypobranchial glands of several marine gastropods'mollusks of the generamurex, bolinus, purpura, plicopurpura, and.thiasand it is probably the mostexpensive dye in the history of mankind. Indian dyers were perfect in the process of bleaching, mordanting, and dyeing natural colorants, historical processing, and sustainable prospects. by the fourth and fifth century AD. Records of compound colours of black, purple, red, blue, and green with various shades of pink and gold are available in contemporary accounts of the tenth century, amongst them, the anonymous; Hudud-ul-Alam is the most important document in the history of dyeing. In the period of Mughal reign, dyers used Madder, Myrobalan, Pomegranate, Turmeric, Kachnar, Tun, Dhao, Indigo, Henna, Catechu, Saffron, and Patang as natural dyes and pigments and the mordants which were used in those days were soluble salt of Aluminium, Chromium, Iron and Tin which adhere strongly with fibres and give fast colors. The trends portray two things, the colourfulness and the fastness of the materials.

\section{Skill Acquisition and Organisational Performance}

Skill acquisition or training has a wider meaning than learning and the procedural concepts associable with it. A socio-surgical analysis of this term would include patience, observing, thinking, discussing, mentoring, touring (for learning), alertness of mind, and equipoise where reaction glaringly normally expected. All these taken together aimed at attaining a change from a natural initial state to a deserved or an intended one which indication will be a behavioural service or tangible products output effect. Training is an excellent source of motivation. When an organization sends an employee for training that employee will be motivated to perform. Advance team concepts, a training firm based in the USA opine that trained employees have a greater capacity to be 
empowered and perform with excellence, which also motivates them since it builds their sense of ownership, confidence, and willingness (Ndibe 2014). The obvious skill gaps and consequential poor performance however showed that things are not in order in most of our private and public organizations in Nigeria and particularly in the dye industry. Despite knowing the importance of employee training, drilling companies still lack effective employee training and development policy, also management training such as leadership, supervision, and labour law seems not to be their priorities. (Janes 2018).

\section{Skill Acquisition and Innovations in the Dyeing Business}

The classification of skills is into three conventional types. We have discrete, serial, and continuous motor skills. The discrete motor skill uses simple movement patterns such as writing. This is just the performance of one action in isolation from other actions. They are always with a definable beginning and end. Serial skills are performing multiple discrete skills at a point in time. A serial skill includes multiple jumps respectively. A continuous motor skill is that without a definable beginning or end. This includes walking, running. Any of these three classifications can be reclassified into just two namely fine and gross motor skills. According to Mahatevan and Ming (2019), training prepares employees to be ready for any hurdles and also reduces employees' resistance to change.

\section{Education, Technology, and IndustrialDevelopment}

Akinyele and Oladimeji (2016) posited small and medium enterprises (SME) sector is usually relied upon because of extant scholarly knowledge of its capacity to contribute to economic development. The value of intellect and easy decoding of guided information can hardly be overemphasized especially with the new leapfrog technology global awareness. According to Ogunbiyi (2016), technological development is manifest transformational. In treating formal school educational value as a key to skill acquisition and performance, formal education is an effective instrument for boosting the brainpower and quality of mind. This view is supported by the proverbial saying "If education is costly, try ignorance" and is said according to Ahmadi (2015) the history of Nigeria development runs parallel to the history of Nigerian educationbecause the countrycould not develop without a proper grounding in education that can guarantee high-quality workforce

In some popular texts, technology has been defined as the organisation and application of knowledge for the achievement of practical purposes. It includes tools methods, techniques, and processes used in solving problems and obtaining desired outcomes. It is worth mentioning that technology is a vital requirement of any purposeful organisation, private or public business-oriented. In line with this, it was said what Microsoft does so lucratively now barely exists as a business 20years ago and what Google does today did not exist at all less than a decade ago (Cole \& Kelly 2011). These emphasize the crucial positioning of information technology and the whole broad spectrum of technological innovations and the soft skill concept. Further it is said technology does not end there. Artifacts have to be produced. This requires a large system including hardware (such as machinery or manufacturing plant) and finality "software" (know-how human knowledge and skills). Technology includes what things are made and how they are made (Grubler, 2015). This reflects the revolutionizing effect of the new business world of technology. The dimension of technological product-oriented innovativeness in SMEs includes cost-effectiveness, quality improved versions of 
existing products or altogether new products, creating a variety of products, creating demand in the new market-leading to production and income growth (Obunike\&Udu 2019). Innovation and technology have come with their economic effects of immeasurable benefit in terms of cost, time, and resource use dye processes not an exception.

\section{Practice Concept}

There is civility in doing anything in life, including management particularly operations, to enhance performance. It is equally established in skill and learning. Ibrahim, Boerhannoeddin\& Bakare (2017) on training methodologies discusses time-space learning approach which is a break or spaces to practice what they have learned, established that in the real organizational context employee should be able to seize the benefit inherent in the use of time-space learning training methodology. The mindset should be that only those who have the patience to do simple things perfectly ever acquire the skill to do difficult things easily. Bamboo takes three good years to develop its root down the soil but shoots up fastest its stem and leaves fully within six months.

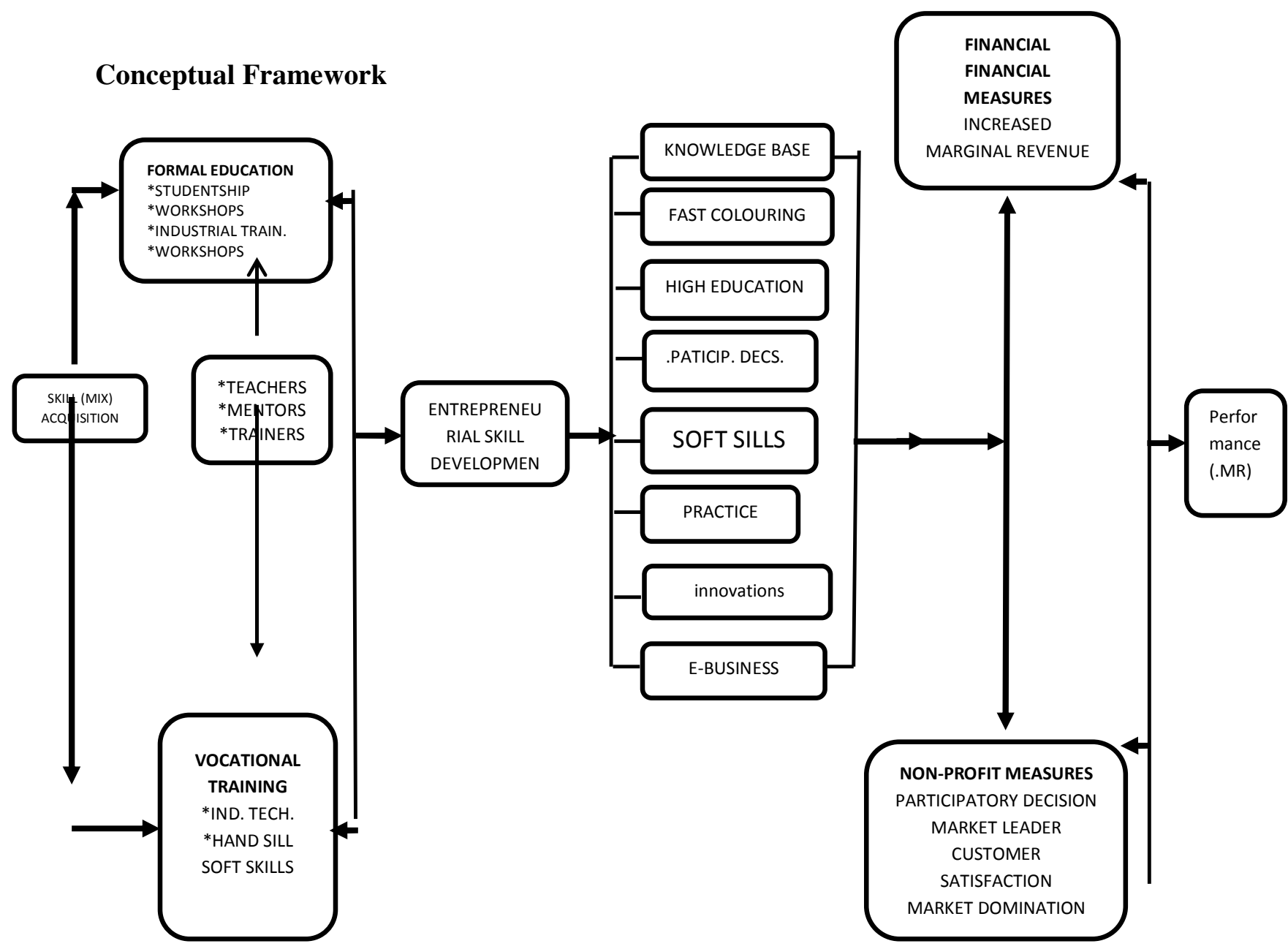

Source: The Author's Conceptual View:The above is the author's conceptualization concerning synergies between skills acquisition and performance in dyeing. 


\section{Methodology}

\section{Research Design}

The research design was cross-sectional. The data was gathered across the sample population at a point in time making it a cross-sectional design;

\section{Research Method}

The questionnaire used procedural guides on how to fill the questionnaire, applying a graphic device to control the instruments used, and guide responses as well as the structured questionnaires which were closed-ended.

\section{Population of Study}

A sample population size of 146 respondents was considered for this survey. Each area or zones of the geographical location of this study, Abeokuta South Local Governmentsegregated into five units categorized as A to E.

\section{Sampling Technique}

The researcher considers the representativeness of the investigation as a signpost to the reliability of the findings adopted stratified sampling. The variable of interest here was education attainment from either the angle of formal or vocational/technical education, practicing experience, and gender. The degree of homogeneity was high the probability of sampling error became low. The entire population size was sampled for the reason of representativeness.

\section{Instrument of Data Collection}

The questionnaire was the major instrument of the data collection. Surveys of the population of 146 respondents were going to be collected. The questionnaire was such a well-structured one consisting of five (5) point Likert scale coded as Strongly Agree (SA) to Strongly Disagree (SD).

\section{Data Analysis}

\section{The Multiple Regression Analysis}

Table 4.1.1Main result of the SPSS stepwise multiple regression

\begin{tabular}{|l|l|l|l|l|l|l|l|}
\hline Step & & $\mathrm{N}$ & $\begin{array}{l}\mathrm{R}^{2} \\
\text { Change }\end{array}$ & $\begin{array}{l}\mathrm{F} \\
\text { Change }\end{array}$ & $\mathrm{Df}(1)$ & $\mathrm{df}(2)$ & $\begin{array}{l}\text { Sign of } \\
\text { Change }\end{array}$ \\
\hline 1 & practice & 636 & 0.21 & 164.8 & 1 & 634 & 0.001 \\
\hline 2 & $\begin{array}{l}\text { High } \\
\text { education }\end{array}$ & 636 & 0.05 & 36.13 & 1 & 633 & 0.001 \\
\hline
\end{tabular}

Source: SPSS Package (Version 24)

$\mathrm{F}=\mathrm{R}^{2}$ change/ Number of predictors/ (1-R2)/ (N- number of predictors-1) (Ducan 2003).

In the regression, analysis $\mathrm{N}$ represents the number of cases. The number of cases in this experiment is 636 i.e $\mathrm{N}=636$ 
The proportion of significance of practice is explained by the formulae above. The difference between this F change and SPSS (Statistical Package for Social Science) F change is caused by the number of decimal places used by the SPSS package for rounding up the figure higher than the calculated $\mathrm{F}$ change.

$\mathrm{Fp}=0.206 / 1(1-0.26) /(636-1-1)=164.8$

Note that $F_{p}$ represents Fpractice $=0.206 /(0.794) / 634=0.206 / 0.00125=164.8$

The $\mathrm{F}$ ratio has two degrees of freedom 1 for the half of the numerator formula (That is number of predictors which is just 1 for the first entered predictor in this case) the degree of freedom is always 1 for the numerator in multiple regression analysis

The two degrees of freedom for practice as predictors are 1 and 634. F ratio is significant at less than 0.01

$\mathrm{F}_{\mathrm{He}}=0.54 / 1 /(1-0.054) /(636-2-1)=0.05 / 1-0.054 / 633=0.054 / 0.946 / 33=0.054 / 0.00149=36.1$

The $\mathrm{F}_{\mathrm{He}}$ means $\mathrm{F}$ ratio for Higher education to indicate the proportion of significance of the predictor - the second entered predictor given a stepwise two predictor

Table 4..2: SPSS Output Value and Calculated Value

\begin{tabular}{|l|l|}
\hline SPSS OUTPUT VALUE/TABLE VALUE & CALCULATED VALUE \\
\hline 164.7 & 164.8 \\
\hline 16,3 & 36.1 \\
\hline
\end{tabular}

Source: SPSS Package (Version 24) and Multiple Regression Formulae

The difference in the SPSS and calculated value with SPSS higher value is then the calculated value is due to the rounding up the decimal place use whereas SPSS use more decimal places. The essence of studying these variables as predictors of the marginal return in the dyeing industry is reflected in the analysis of their strong relationship; the predictors namely practice higher education, are tested to be significant, the two being significant at less than 0.001 but with different $F$ ratio which indicated their level or proportion of significance as analyzed above using the calculated and SPSS output models.

The higher the $\mathrm{F}$ ratio the more likely is the significance of this corresponding variable (the predictors). This comes in taking into consideration other random variables that may affect each predictor highly packed within such variable, To sum up, the stepwise model of multiple regression adopted to see how marginal returns, the dependent variable, respond to the predictors' influence, as applicable in the business economics, Paul and Phillip (2009) explained the key to understanding the pattern of change in QAP and MP (the level of average productivity and marginal productivity) is the phenomenon known as the law of diminishing returns. The law states as an additional unit of a variable input are combined with a fixed input at some point the additional output(i.e marginal product) start diminishing Therefore in the case of dye tie-dye products we assume the workshop building and land on which the land it is built on as a fixed factor with which the variable inputs would be, verified namely the high education and practical training (Practice) as intangible human 
resource development variable, crucial to development planning and its implementation plan in management, variables with which the tangible items, thefixed factor, were also varied yielding the increase in productivity up to an optimal level when it should be ideally controlled.

Co relational statistics ( $\mathrm{R}^{2}$ change) as abstracted in dyeing gave the strength of practice as 0.2 and that of the High education 0.05 ; it does not mean practice to education is $4: 1$ it only indicated the abstract. It is a relative measure. At an off-head judgment, a reader may feel Practice can be as high as 0.80 to education say 0.01 . However, this figure is abstract to indicate a direction of strengths measure only between the predictors concerning the criterion variable and it was numerical without a unit of measurement of all the variables under consideration.

\section{Model Summary}

Table 4.3: SPPSS Output

\begin{tabular}{|l|l|l|l|l|l|l|l|l|l|}
\hline Model & $\mathrm{R}$ & $\begin{array}{l}\mathrm{R} \\
\text { square }\end{array}$ & $\begin{array}{l}\text { Adjusted } \\
\mathrm{R} \text { Square }\end{array}$ & $\begin{array}{l}\text { Std } \\
\text { Error of } \\
\text { Estimate }\end{array}$ & $\begin{array}{l}\mathrm{R} \\
\text { Square } \\
\text { Change }\end{array}$ & $\begin{array}{l}\mathrm{f} \\
\text { change }\end{array}$ & $\begin{array}{l}\text { change } \\
\text { statistics } \\
\mathrm{df}_{1}\end{array}$ & $\mathrm{df}_{2}$ & $\begin{array}{l}\text { sig f } \\
\text { change }\end{array}$ \\
\hline 1 & $0.454^{\mathrm{a}}$ & 0.206 & 0.205 & 0.852 & 0.206 & 164.683 & 1 & 0.634 & 000 \\
\hline 2 & $0.510^{\mathrm{b}}$ & 0.260 & 0.276 & 0.813 & 0.019 & 16.343 & 1 & 0.633 & 000 \\
\hline
\end{tabular}

Source: SPSS Package (Version 24)

a. Predictors (constant), DYEING CENTRES, WELL EQUIPPED, FACILITATE PRACTICEPredictors (constant), DYEING CENTRES, WELL EQUIPPED, FACILITATE PRACTICE, HIGH EDUCATION GREASE PRODUCTIVITY.

b. Predictors (constant), DYEING CENTRES, WELL EQUIPPED, FACILITATE PRACTICE, HIGH EDUCATION GREASE PRODUCTIVITY,

\section{Discussion of the Research Findings}

In the stepwise regression, Practice was entered first and explained $21 \%$ of the variance in the dyeing industry marginal returns performance $\left(\mathrm{F}_{1,634}=164.7, \mathrm{P}<0.001\right)$. High education was entered second and explained a further $5 \%\left(\mathrm{~F}_{1,633}=16.3, \mathrm{P}<0.001\right)$ of the variance in the dyeing industry performance in terms of the marginal returns. Practice as a predictive variable was entered first which explained $21(0.2)$ percent of the variance in the marginal returns $\left(\mathrm{df}_{1}, 634=164.7, \mathrm{p}<0.001\right)$ which indicated its significance. The null hypothesis was rejected as it was not supported by the research finding; the Alternative hypothesis, therefore, confirmed that practice had a significant effect on marginal returns in the dyeing industry.High education was entered second and it indicated 5 (0.05) percent of the strength of its influence on the productivity-related (marginal returns) variable $\left(\mathrm{df}_{1}, 633=36.1, \mathrm{p}<0.001\right)$ In essence, the marginal returns was positively impacted upon in an economic performance sense. High education (high technical education in particular) attainment was found significant. The null hypothesis, therefore, was invalid and as such not supported and rejected. High education was significant in the dyeing industry in terms of the marginal returns 


\section{Summary of Findings, Conclusion and Recommendations Summary of findings}

Practice as the basis of core practical skills was highly significant. (Found to be 0.2 ) The relative effect of practice was found to be significant on the marginal returns in the dye firms. High education attainment (abstracted to 0.05) was also found to be significant as well for achieving the objective of increased marginal returns in the dye industry.

\section{Conclusion}

Practice had a strong effect on the marginal returns in the dyeing industry.

High education had a significant effect on the marginal returns in the dye industry

The research revealed that skill acquisition had a significant effect on the performance of the dyeing industry in Abeokuta based on the verified variables of Practice and High education.

\section{Recommendation}

Adequate time Practice-based training in tie-dye firms should be intensified.

High education should be subsidized or become free as a matter of policy.

The establishment of well-facilitated practical-based dyeing training centres highly recommended.

Cash backed budgetary shares for practical-based technical high education should be seen to be increased and implemented by the policymakers as well as the policy drivers.

\section{References}

Ahmadi, A. (2015).Issues and prospects of effective implementation of new secondary curriculum in Nigeria. Journal of Education and Practice, 29.

Akiyele, S., T., Akinyele, F., E., and Oladimeji, D. 1. (2016). Infrastructural development as a predictor to small and Medium Enterprises Performance in Nigeria, 5.

Cole, G., A. and Kelly, P. (2011).Management theory and practice, Centage Learning, 447.

Ducan, C. (2003). Understanding social research: advance quantitative data analysis, Open University Press, 1-254.

Gubler, A. (2015). Technology and global change, Cambridge University Press, 17.

Ibrahim, R., Boerhannoeddin, A., and Bakare, K., K. (2017). The Effect of soft skills and training methodology on employee performance. European Journal of Training and Development, 41(4), 388-407.

Irikefe, B., O. (2017). A Handbook of skill acquisition, training and empowerment programme, International Centre for Sustainable Development, Nigeria, Abuja, 31.

Janes, O., S. (2018). Impact of employees training on organizational performance - A case study of Drilling Companies in Geiya, Shiyanga and Mara Region in Tanzania, International Journal of Managerial Studies and Research, 6(1), 36-41.

Mohd, Y., Mohd, S., and Faqeer, M. (2017). Natural colorants: historical, processing and sustainable prospects.http/link.springer.colorant/content/pdf/10.1007/513659-017-0119-9 pdf, 2017(7), $123-145$.

Napoleon, H. (2020). The law of Success, Repro Books 1td, 1-660.

Ndibe, B., C. (2014). Effects of employees training on organizational performance in soft drink bottling companies in Enugu State, Nigeria, Faculty of Business Administration, University

of Nigeria, Enugu Campus, 1-116. 
Obunike, C., F., and Udu, A., A. (2019). Technological innovativeness and growth, A study of smallscale manufacturing firms in Lagos, Lcc Consulting Publishing Company, Business Perspective.

Ogunbiyi, B. (2016). Management in action, University Press, Ibadan, 106.

Paul, J., K., and Phillip, K., Y. (2009). Managerial economics: economics tools for today's decisionmaker, 1-598.

Vera, K. (2021). Sir William Henry Perkin (1938-1907), Chemistry View, 1-3. 